\title{
Espacialidades
}

\section{UM ESTUDO SOBRE O COTIDIANO E A PROSTITUIÇÃO NO BECO DA ENERGIA, EM FEIRA DE SANTANA (BA) $1950-1960$}

A study of the daily and prostitution in energy's alleyway, in the city of Feira de Santana, Bahia 1950 - 1960

\author{
Lucymara da Silva Carvalho ${ }^{1}$ \\ Maria Aparecida Prazeres Sanches ${ }^{2}$
}

Artigo recebido em: 04/08/2020.

Artigo aceito em: 01/12/2020.

\section{RESUMO:}

O cotidiano das décadas de 1950-1960 da tradicional zona de prostituição da cidade de Feira de Santana (BA), o Beco da Energia, ocupa o cerne da discussão deste artigo. Objetivamos analisar a história desse espaço contrapondo as narrativas historiográficas escritas sobre o Beco a memória dos seus antigos moradores e dos demais indivíduos que o frequentavam, problematizando assim, os diferentes sentidos tecidos sobre essa zona feirense. Nosso trabalho se insere no campo da História Social da Cultura e os estudos da Memória. Como fontes utilizamos as entrevistas orais, os periódicos do Jornal Folha do Norte e os Códigos de Posturas Municipais. Para tal análise, lançamos mão dos debates teóricos feitos por historiadores e cientistas sociais. PALAVRAS-CHAVE: Beco da Energia; Cotidiano; Prostituição.

\section{ABSTRACT:}

The daily life um the 1950s-1960s of a traditional prostitution zone of the city of Feira de Santana (BA), called Beco da Energia that occupies the core of the discussion of this article. We aim to analyze the history of this space against the historiographic

\footnotetext{
1 Mestranda em História social, na linha de pesquisa Cultura, Identidades e Linguagens, do Programa de Pós-Graduação em História da Universidade Estadual de Feira de Santana (UEFS). Minha área de interesse se direciona as seguintes temáticas: gênero, raça, prostituição, memória, família, decolonialidade, cidade, feminismo negro, escrita afro-brasileira. Atualmente, desenvolvo pesquisa voltada para a discussão do conceito de família e prostituição na cidade de Feira de Santana entre as décadas de 1950-1970. Currículo Lattes: http://lattes.cnpq.br/6089571299466369. Email: lucymara.c@hotmail.com.

2 Possui graduação em Licenciatura Em História pela Universidade Federal da Bahia (1990), Mestrado em História pela Universidade Federal da Bahia (1998) e Doutorado em História pela Universidade Federal Fluminense (2010). Atualmente é professora Adjunto B da Universidade Estadual de Feira de Santana. Tem experiência em ensino e pesquisa na área História, com ênfase em História da Bahia e História da República, atuando principalmente nos seguintes temas: relações conjugais, mulheres pobres, relações raciais, gênero, namoro, defloramento, família, casamento e cultura popular. Currículo Lattes: http://lattes.cnpq.br/5420819419671269. E-mail: prazerescida1@gmail.com.
} 
narratives written about Beco to the memory of its former residents and of the other individuals who frequented it, thus problematizing the different meanings woven about this area. Our work is inserted in the field of the Social History of Culture and the Studies of Memory. As sources we used oral interviews, journals of the Folha do Norte newspaper and the Codes of Municipal Postures. For this analysis, we use the theoretical debates made by historians and social scientists.

KEYWORDS: Beco da Energia; Daily; Prostitution.

\section{Introdução}

Na década de 1980 segundo Cunha (2000), se tornava cada vez mais crescente no Brasil a incorporação da corrente historiográfica proposta pelo historiador Edward Palmer Thompson sobre uma história vista de baixo, corrente que influenciou fortemente os historiadores que se interessavam pela temática das mulheres na História. Essa perspectiva propunha uma análise historiográfica na qual a vida de homens e mulheres comuns e até então invisíveis na história, pudessem ser olhados de uma forma mais atenta, na tentativa de perceber as negociações e disputas políticas que se travavam, entre os indivíduos das classes sociais mais abastadas e os demais grupos subalternizados.

É nesse cenário de mudanças historiográficas, que a história da prostituição feminina no Brasil passou a ser discutida em diversos trabalhos que analisaram a dinâmica entre o espaço urbano e a prostituição em diferentes cidades, sobretudo durante o século XIX e XX ${ }^{3}$. Nosso artigo se insere então, dentro desta seara. Objetivamos compreender o cotidiano de um espaço localizado no centro da cidade de Feira de Santana (BA), que abriga a prática prostitucional desde esse período. Falamos da rua denominada como 13 de Novembro, que ficou conhecida como o Beco da Energia, devido a existência até meados do século passado, da sede da empresa que fornecia energia elétrica na urbe feirense.

Entre as décadas de 1950 e 1960, período da nossa pesquisa, a rua abrigava cerca de oito imóveis, nos quais os seus moradores utilizavam como residência e, ao mesmo tempo, para pequeno comércio. Dentre essas oito residências e comércios, quatro casas eram

\footnotetext{
${ }^{3}$ Para uma discussão sobre a historiografia da prostituição no Brasil ver: RAGO, M. As mulheres na historiografia brasileira. In: Silva, Zélia Lopes (org). Cultura Histórica em Debate. São Paulo: UNESP, 1995. RAGO, M. O efeito-Foucault na Historiografia Brasileira. In: Tempo Social. São Paulo: USP, 1995, nº 7 , pp.67-82.
} 
também um espaço que acolhia a prostituição e o comércio de bebidas, chamada pelos moradores de ponto de encontro ou casa de diversão, levando-nos a formular a nomenclatura casas/bares de diversão na tentativa de contemplar essa multiplicidade de sentidos atribuídos as mesmas. Essas casas eram administradas por mulheres negras e brancas que pareciam ser queridas por todos na região, sobretudo uma conhecida como Madame Greice que permaneceu no Beco até a década de 1990.

É também nesse período, que grande parte dos trabalhos historiográficos apontam que a prostituição passa a ser combatida pelo poder municipal. E é nesse ponto que reside nosso problema, ou seja, questionamos se a prostituição era realmente entendida como um problema para os moradores do Beco da Energia e para os demais indivíduos que tinham acesso ao mesmo. Buscaremos aqui, através do campo de discussão entre a Memória e a História pensar o cotidiano do Beco, não pelo viés dos discursos produzidos por médicos e juristas, mas sim pelos moradores que geriam suas vidas familiares e profissionais no mesmo. Nosso trabalho se insere, portanto, no campo da História Social da Cultura e os estudos da memória. A memória aqui, será pensada em duas dimensões. A primeira dialoga com as conceituações propostas por Halbawachs (1968), que a entende como fruto de uma construção que perpassa o plano individual e que deve ser entendida a partir da coletividade, e a segunda que diz da sua possibilidade de ser utilizada, enquanto uma fonte histórica nos estudos acerca do cotidiano.

A utilização da fonte oral na nossa análise foi fundamental para trazermos uma visão do Beco da Energia a partir das múltiplas vivências e subjetividades dos seus antigos moradores. Questão que para o historiador Alessandro Portelli (1996) é extremamente necessária, pois ele observa que a história oral e as memórias, não nos oferecem apenas um esquema de experiências comuns, mas sim um campo de possibilidades compartilhadas, reais ou imaginárias. Assim a memória dos homens e mulheres entrevistados, mas do que nos informar sobre o cotidiano no Beco, também nos deram uma oportunidade para compreendermos como as práticas sociais exercidas por estes, construíram sentidos múltiplos para espaço, que falavam das suas experiências de vida, como donas de casas/bares de diversão, vizinhos ou filhas das mesmas.

É necessário sinalizar, que a utilização da oralidade enquanto fonte, só nos foi permitida, na condição de preservação dos nomes reais dos nossos depoentes. Assim, todos 


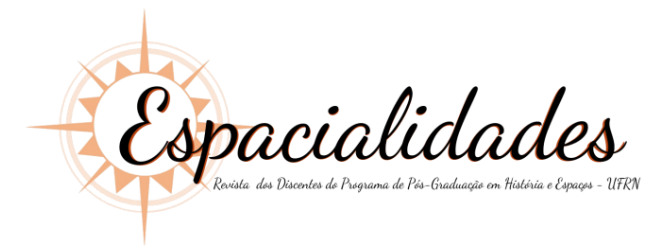

os nomes dos entrevistados são fictícios ${ }^{4}$. Os outros documentos consultados, sendo estes: os periódicos do Jornal Folha do Norte dos anos de 1950-1960, e o Código de posturas municipais da cidade dos anos de 1937 e 1967, foram utilizados por nós, na tentativa de compreendermos como o discurso de modernidade, propagado pelo Folha do Norte e as normas municipais estabelecidas pelos Códigos de posturas se posicionavam frente a existência de casas de prostituição no centro da cidade ${ }^{5}$. Para embasarmos a nossa discussão, lançamos mão de diferentes autores, sendo estes: Pesavento (2001), Certeau (1998), Rago (1991), Bacelar (1982) e Fonseca (1996). A leitura desses clássicos foi essencial para pensarmos a relação entre os espaços de prostituição e os múltiplos significados elaborados a respeito deles, ao longo do tempo.

Direcionamos a nossa escrita inicialmente, para o debate acerca dos sentidos que foram atribuídos aos becos na historiografia, para além das análises feitas sobre a cidade de Feira de Santana. Em um segundo momento, aprofundamos tal discussão, voltando-nos especificamente ao Beco da Energia através da análise das nossas fontes. Por fim, nos atemos a uma análise do Beco da Energia enquanto uma zona de prostituição que também abrigava lugares de memória de famílias, utilizando-nos dos debates acerca da memória elaborados por Nora (1993) e Pollak (1992).

\section{Os Becos e seus sentidos na cidade}

Falar sobre o Beco da Energia não é possível sem levarmos em consideração, a multiplicidade de sentidos e usos que um espaço pode adquirir dentro da cidade, de acordo

\footnotetext{
4 Nesse artigo lançaremos mão das entrevistas com os seguintes sujeitos: Arnaldo um comerciante local e antigo vizinho do beco da Energia. Clésia dona de uma casa de prostituição desde o período de análise da nossa pesquisa. E três mulheres da família de Madame Greice, uma das antigas donas de casas/bares de diversão entre os anos de 1950-1980, sendo estas Maria e Suzana suas filhas e Marina sua nora.

${ }^{5}$ A realização das entrevistas orais feitas por nós, se concentrou entre os anos de 2015-2018, pois foi parte fundamental da pesquisa que desenvolvemos sobre o Beco da Energia, que resultou trabalho de monografia de uma das autoras, sendo este: CARVALHO, L.S. Mas menina, o Beco era uma Rua como outra qualquer! Memórias, Cotidiano e Prostituição no Beco da Energia, Em Feira de Santana (BA) 1950-1960. Monografia (graduação) Universidade Estadual de Feira de Santana, Feira de Santana, 2019.
} 
as significações que os sujeitos elaboram cotidianamente sobre os mesmos ${ }^{6}$. Principalmente, se levarmos em consideração a premissa que já vem sendo debatida pelos estudos geográficos desde a década de 1980, de que os espaços urbanos, mas do que físicos são construtos socioculturais das sociedades que os cercam e povoam ${ }^{7}$.

Segundo Pesavento (2001) as representações sobre os espaços da cidade, estão fundamentalmente relacionadas aos aspectos da materialização de um lugar a partir das condições sociais e espaciais destes (tipos de habitação, rua, terreno, práticas, personagens), mas que só ganham sentido se considerarmos o processo da construção de um ideal a ser almejado e de uma alteridade a ser rejeitada e, portanto, marginalizada dentro do território da cidade. Analisando as representações dos territórios de alteridade na cidade de Porto Alegre no final do século XIX, a historiadora elaborou uma importante reflexão sobre os Becos que nos será cara neste trabalho, uma vez que é uma das poucas a oferecer uma conceituação sobre este espaço dentro de uma perspectiva que leve em conta a temporalidade.

Pesavento (2001) afirma que, existiram nas cidades modernas, territórios que não condiziam com a expectativa dos ideais de civilidade e moralidade, sendo denominados por ela como os "malditos lugares da urbs". O interessante na sua pesquisa é que, o lugar apontado como templo da maldição na cidade sulista foram justamente os becos encravados no centro da mesma. A autora percebeu, que essas ruas ao longo do tempo, deixaram de fazer referência ao seu significado topográfico e mais original do termo, enquanto uma rua estreita, com ladeira e não planejada dentro da expansão urbana, para ser relacionada ao resguardo dos excluídos urbanos que acolhiam os indivíduos pobres, "fétidos e de mau viver" das camadas sociais mais baixas da sociedade, no qual o epicentro da contravenção e do crime e a origem de toda a desordem se encontravam na figura das prostitutas.

\footnotetext{
${ }^{6}$ Lançamos mão neste trabalho das análises realizados por Certeau (1998) que entende o cotidiano como um campo de negociações e conflitos que se faz numa constante produção, entre os indivíduos e as diversas instituições que compõem determinada sociedade e os locais que adquirem feições diferentes e variáveis de acordo a forma como este será utilizado.

${ }^{7}$ Para compreender os diferentes debates teóricos em torno do conceito de espaço ver: CORREA, R. L. A. Espaço: Um Conceito - Chave. In: Iná Elias de Castro; Paulo Cesar da Costa Gomes. (Org.). Geografia: Conceitos e Temas. Rio de Janeiro: Bertrand Brasil, 1995, v. 1, p. 15-47.
} 
Os becos eram um reduto, das ditas mulheres "desmoralizadas" e apresentavam um constante perigo às famílias da cidade, que estava relacionada às condutas sexuais das mulheres prostitutas que ameaçavam o ideal de família burguesa ${ }^{8}$. Entretanto, o que fomos percebemos durante a leitura do seu trabalho é que, os becos enquanto um espaço urbano, foram analisados apenas, em contraposição ao que se entendia como civilizado e moderno, deixando as especificidades cotidianas dos sujeitos que habitavam estas ruas estreitas fora de questão. Ao se utilizar da fonte jornalística, a historiadora ao mesmo passo que produz críticas sobre a marginalização da população pobre e negra em Porto Alegre, acaba também delegando aos espaços ocupados por estes, uma única identidade, que era fundamentalmente marginal. Sem se ater, que talvez para os moradores dos becos estudados os sentidos de tal espaço estivessem atrelados a sobrevivência, vida em família, trabalho ou mesmo divertimento. Afinal os espaços são também resultantes das interações sociais tecidas nos mesmos.

Essa ressalva se mostrou importante, pois percebemos que se os becos enquanto espaços urbanos, são grosso modo, representados na historiografia em conformidade com as formulações elaboradas sobre este espaço por indivíduos que traziam sempre uma imagem preconceituosa e sexista do mesmo. Segundo Fernandes (1992) os espaços físicos são também uma construção do imaginário coletivo e individual, os quais estão em pleno processo de circularidade, pois para ele constrói-se como representa e representa como se constrói. A questão aqui, no entanto, não é entender a construção física dos becos, mas compreender quais representações construídas historicamente, inclusive por nós historiadores, ocultam as inúmeras vivências e percepções dos sujeitos que realmente viveram nos espaços de prostituição sejam eles becos ou não. Resta nos questionarmos se a prática de pensarmos esses espaços a partir da lupa da marginalidade e exclusão é a única saída. Se trata, portanto, de uma incitação a problematização do que de uma solução pronta e acabada.

Essa problemática também foi discutida por Carvalho (2016) numa análise sobre as construções historiográficas acerca dos becos da cidade feirense. Segundo a historiadora, os becos feirenses foram estudados, apenas dentro de uma perspectiva que buscava

\footnotetext{
${ }^{8}$ Para a discussão sobre o ideal de família burguesa ver: CAULFIELD, Sueann. Em defesa da Honra. Moralidade, Modernidade e Nação no Rio de Janeiro (1918-1940). Campinas: Ed. UNICAMP, 2000.
} 
compreender quais os espaços de Feira, passaram a ser alvos de medidas do poder municipal, na tentativa de normatizar as formas de sociabilidades que destoassem do ideal de honra e moralidade burguês. Assim, ainda se sabe muito pouco sobre a interação que ocorria entre os feirenses que estavam ligados a prostituição e aqueles que se mantinham afastados.

Em consonância as análises feitas por Carvalho (2016), observamos que o Beco da Energia aparece tanto no trabalho de Oliveira (2008), quanto no de Silva (2009), na parte final das suas discussões bibliográfica, nas quais as autoras dedicam-se a pensar acerca dos “outros", que aos poucos, segundo as mesmas, estavam sendo retirados das ruas do centro feirense. No trabalho de Lima (2014), o Beco aparece situado dentro de uma zona denominada como Complexo Rua do Meio, que segundo o autor englobava ruas e becos que alocavam sujeitos e práticas “imorais" ou subversivas, como o jogo do bicho, vadiagem e a prostituição, no entanto não encontramos mais informações além dessas prerrogativas.

Oliveira (2008), dedicando-se a pensar a construção do discurso de modernidade em Feira de Santana durante as décadas de 1950 e 1960, aponta que neste período os espaços de prostituição foram alvo de uma intensa perseguição que provocou a desterritorialização das casas de prostituição, das ruas nas quais esta prática acontecia a algum tempo, sendo estas: a Rua do Bom e do Barato, a Rua do Meio, o Beco do Ginásio, e o Beco do Mocó, todas estas situadas no centro da cidade. A autora observa que o Beco da Energia foi o local no qual as mulheres que se prostituiam migraram na tentativa de continuarem a exercer a prostituição.

Silva (2009) por sua vez, voltando seu foco para a produção e a reprodução dos discursos moralistas na cidade de Feira de Santana entre as décadas de 1960 e 1970 também identifica o Beco da Energia apenas como espaço de prostituição. A autora mesmo se utilizando de entrevistas com uma dona de "casa de prostituição" do Beco, não aprofunda sua análise sobre o mesmo ${ }^{9}$. O que se pôde captar da sua escrita é a ênfase dada pela sua entrevistada em afirmar que os homens clientes que frequentavam as casas de diversões no Beco eram sujeitos financeiramente bem posicionados na sociedade e também as diferentes significações que as mulheres mundanas do Beco teciam sobre a ideia de honra. Silva (2009)

\footnotetext{
${ }^{9}$ Silva (2009) se utilizou das análises sobre a prostituição em Feira de Santana feita pela socióloga Railda Matos no seguinte trabalho: MATOS, Railda. M. Elas sonham acordadas em Santo Antônio dos prazeres: mulheres em prostituição. Salvador. UFBA, 2000 (Dissertação de mestrado).
} 
observa, que para uma mulher prostituta, ou uma dona de casa de diversão ser honrada estava muito mais relacionada a trabalhar e não roubar, do que a sua vivência no âmbito sexual.

A partir destes dois trabalhos, temos inicialmente, um Beco inserido em um contexto de intensa perseguição a prostituição, no qual os indivíduos estigmatizados que ali viviam conseguiram elaborar meios para permanecer no local. Entretanto, ao analisarmos as nossas fontes, essa tese de perseguição as casas de prostituição, não se mostrou evidente, constituindo um problema ao qual, toda a discussão desse artigo se baseia. Questionamentos que discutiremos no tópico a seguir.

\section{Existiu mesmo a perseguição às casas de prostituição na urbe feirense?}

É interessante como as pesquisas históricas podem construir versões completamente diferentes sobre o mesmo contexto e espaço, sobretudo quando a construção da narrativa historiográfica se utiliza das memórias dos homens e mulheres que puderam vivenciar os acontecimentos, que nós enquanto historiadores podemos apenas analisar e compreender. Questão pontuada por Michael Pollak (1992) um estudioso da memória, ao ressaltar que a história oral tem permitido que o conhecimento histórico, adentre à cotidianos antes delegados apenas ao esquecimento, como é o caso dos espaços de prostituição nas cidades brasileiras.

$\mathrm{Na}$ nossa pesquisa sobre o Beco da Energia, essa percepção ficou muito clara, na medida em que, ao entrevistar as pessoas que moravam no Beco ou próximo do mesmo, percebemos que aqueles indivíduos não se entendiam como "os outros" da cidade e tampouco atribuíam a prostituição o único sentido do Beco para eles, o que contrariava a identidade marginal apontada pela historiografia a respeito das ruas em que abrigavam a prostituição em Feira. Além disso os nossos entrevistados, negavam ter ocorrido uma perseguição as "casas de prostituição" observando que a diminuição desses espaços foi devido ao crescimento do comércio principalmente no final da década de 1960, o que provocou a saída de outras famílias da região do centro, mesmo que os membros da mesma, não tivessem uma relação direta com a prostituição, como era o caso de Madame Greice. 
Segundo Sr. Arnaldo, antigo morador da Rua Marechal Deodoro e vizinho do Beco, as próprias donas de casas/bares de diversão e os demais moradores ao perceberem esse crescimento comercial, passaram a vender ou alugar as suas casas, se mudando para outros bairros, mas permanecendo muitas vezes como comerciantes nessas ruas, como é o exemplo do seu pai ${ }^{10}$. Já Dona Clésia, dona de uma casa/bar de diversão desde esse período, ao ser questionada sobre o suposto fim das "casas de prostituição" no centro da cidade observou que, realmente esses espaços foram se acabando, mas que:

(...) todas essas travessas, Beco de Ginásio, tudo nas travessas de Feira de Santana, tinha casa de mulher, e as famílias, não, não, não ficava com problema, com coisa não ficavam procurando problemas, com coisa não! Nego tava brigando com os amantes, corria entrava numa casa daquelas, era normal, ai deixa pra lá, pá, pá, pá. Não é como hoje, que tem essas besteirada com mulher não! (CLESIA, 2017)

O interessante é que essa fala de Dona Clésia, vai de encontro a afirmação feita por Oliveira (2008) sobre o Beco do Ginásio, uma vez que a historiadora aponta, a partir da leitura do jornal Folha do Norte, que era necessário retirar as mundanas das ruas do centro da cidade. É importante ressaltar também que, a partir da análise das falas do Sr. Arnaldo e de Clésia, podemos supor que essa suposta "vontade" de algumas donas de casas/bares de diversão em se mudarem poderia estar ligada a uma inadequação desse tipo de comércio, aos locais com a movimentação de muitas pessoas, o que poderia afastar os comerciantes/clientes que segundo Dona Suzana, eram aqueles que também iam as casas/bares de diversão com muita descrição para se divertirem com as prostitutas ${ }^{11}$.

Rago (1991), ao estudar a prostituição na cidade paulista, durante as décadas de 1890 a 1930, alerta que nesse tipo de ocupação, o sigilo, discrição e a "invisibilidade" eram essências para a permanência da prática prostitucional, pois com a intensa circulação das "mulheres de família" nas ruas de São Paulo no início do século XX, passou a ser necessário que os indivíduos envolvidos com a prostituição agissem de maneira discreta para que a prática não ficasse evidente às "mulheres de família". Para a historiadora, a figura da

10 Arnaldo, comerciante, 60 anos. Entrevista concedida em fevereiro de 2018.

${ }^{11}$ Clésia, dona de uma casa de prostituição, 80 anos. Entrevista concedida em novembro de 2017. Suzana, manicure, aposentada, 63 anos. Entrevista concedida em outubro de 2017. 
prostituta no Brasil republicano, passou a se configurar como um antônimo as moças de famílias, devido a ideia negativa elaborada pelos discursos médicos, literários e criminológicos a respeito da prostituta.

Mesmo escrevendo sobre uma cidade com uma dinâmica diferente, a análise de Rago (1991), nos é cara, pois, tanto Oliveira (2008) como Silva (2009), ao falar sobre Feira de Santana na década de 1950, apontam que foi neste período que a circulação das "mulheres de família" em vias públicas, começou a se intensificar e que, por conseguinte, a perseguição a prática prostitucional, tinha como uma das suas razões o medo dos pais, diante da possibilidade de aproximação das suas filhas e as mulheres prostitutas. Notamos que essa descrição da prática prostitucional proposta por Rago (1991), esteve presente também nas análises de Oliveira (2008) e Silva (2009) e concordamos com as autoras, até o ponto em que se destaca a vigilância em relação ao que poderia ocorrer ou não na frente das "moças de familia", pois todos os nossos entrevistados ressaltaram que existiam regras de convívio para as mulheres prostitutas, ditadas principalmente pelo decoro.

Mas, é necessário problematizarmos que, a partir das memórias dos entrevistados, não ficou claro que esse controle e vigilância promoviam separações em relação às ruas que as "moças de família" poderiam passar ou morar como no caso de São Paulo. Principalmente se levarmos em consideração que, talvez, muitas das chamadas "moças" poderiam ser, assim como Suzana e Maria, filhas de donas casas/bares de diversão, convivendo por isso, com uma relativa proximidade em relação as mulheres prostitutas, sem que deixassem de serem vistas como "mulheres honradas".

Um exemplo disso é que o Sr. Arnaldo, ao falar sobre as filhas de M. Greice, ressaltou mais de duas vezes o respeito que todos na região tinham a elas ${ }^{12}$. Ademais, além desses aspectos mencionados, a análise dos periódicos do Jornal Folha do Norte e os próprios Códigos de Posturas Municipais de Feira também não nos revelaram que ocorreu na cidade feirense a tal perseguição tão alardeada por Silva (2009) e Oliveira (2008), visto que encontramos pouquíssimas denúncias à prostituição nos jornais, e os códigos não faziam

12 Arnaldo, comerciante, 60 anos. Entrevista concedida em fevereiro de 2018. 
nenhuma referência à proibição da prática prostitucional, tendo nos chamado atenção apenas dois elementos no estudo do mesmo ${ }^{13}$.

O primeiro se refere à coibição que o código de 1937, dá a práticas consideradas imorais, e desordeiras, colocando como alvo os indivíduos em situações de vagabundagem ou de desocupação, ao ressaltar que, todo indivíduo encontrado sem ocupação ou em estado de vagabundagem, seria mandado a presença da autoridade policial feirense (APFS, 1937, Capítulo III- Dos hábitos urbanos, art.148º. O segundo diz respeito à abertura que o código tanto o do ano de 1937, quanto o de 1967, dá para a existência das casas/bares de diversão na cidade uma vez que, em nenhum capítulo desses documentos, é proibida a existências das mesmas, sendo pontuado apenas que, era considerado como uma infração a exibição ou exacerbação das "imoralidades", praticadas tanto em bares como em espaços para o divertimento noturno, que pudessem perturbar o sossego público (APFS, 1967, Título IIIDa polícia de costumes, segurança e ordem pública, art. 61).

No código de 1967 é destacado que era proibido executar qualquer trabalho ou serviço que produzisse ruído, antes das 7 horas e depois das 20 horas, nas proximidades de hospitais, escolas, asilos, e casas de residência. Ressalta também que: "na localização de dancings, ou de estabelecimentos de diversões noturnas, a prefeitura terá sempre em vista o sossego e o decoro da população" (APFS, 1967, Título III- Da polícia de costumes, segurança e ordem pública, art. 78). Em paralelo a essa imposição, também notamos que as notícias do jornal Folha do Norte se voltavam muito mais a queixa das movimentações durante a noite, como fica claro nessa denúncia:

Chegam-nos queixas, vindas de várias pessoas contra o mulheril que reside a travessa Leonardo Pereira Borges (antigo Beco do Sossego), que vem praticando, naquele local, desordens e atos contra a sociedade e reboliços durante toda a noite, prejudicando-lhes o sono... A antiga travessa do sossego foi transformada em local de barulho e reboliço. Tais reclamações devem ser enviadas ao $\mathrm{sr}^{\circ}$ delegado de polícia, que talvez, tome as devidas providências. (MCS/CENEF, Desordens, 1951).

${ }^{13}$ O jornal Folha do Norte foi fundando nos anos de 1910 por Tito Ruy Bacelar, João Vital, Arnold Ferreira da Silva e Dálvaro Silva e se mantem em circulação na cidade feirense até os dias atuais, configurando-se como um dos mais importantes veículos de comunicação de Feira de Santana, sobretudo nos assuntos acerca da política, que sempre teve um lugar de destaque nos seus noticiários e colunas. Durante o nosso recorte temporal, o jornal era circulado diariamente na cidade, feição que só se modifica no ano de 1978, ao ser distribuído apenas semanalmente. 
Encontramos apenas uma notícia que apontou o crescimento das "pensões alegres" na cidade no ano de $1951^{14}$. Diante dessas analises, percebemos que durante as décadas de 1950 e 1960, não poderíamos afirmar que ocorreu em Feira de Santana uma perseguição às casas de prostituição. Mas, como o código de 1967 já prevê medidas contra os barulhos noturnos, podemos analisar inicialmente que esses reboliços à noite, ocorriam com muito mais frequência do que os noticiários mostravam e que umas das práticas a provocar barulhos fosse justamente a prostituição. Entretanto, é interessante destacar, que o motivo das denúncias contra os barulhos noturnos pode ter múltiplas interpretações e justificativas.

Alguns dos nossos entrevistados, por exemplo, ressaltaram que muitos jornalistas do jornal Folha do Norte, frequentavam durante o dia e à noite, as casas/bares de diversão no Beco da Energia, e acreditamos que provavelmente as casas localizadas em outras ruas também. Logo, é provável que a intenção dessas denúncias feitas nos jornais, estivesse muito mais relacionada a preocupação desses homens na preservação do sigilo sobre o que ocorria nesses espaços, em que eles iam para conversarem, beberem e se divertirem com as prostitutas, do que com a manutenção do sossego para as "famílias feirenses".

Os nossos entrevistados, sempre chamavam atenção para o fato de que os homens que frequentavam as casas/bares de diversão no Beco eram figuras socialmente importantes na cidade, mas que nem por isso deixaram de construir relações de amizades e de compadrio com as donas desses espaços. Dona Clésia, por exemplo, destacou que muitos deles são políticos na atualidade e que iam direto para o Beco, mantendo por vezes, relações com as mulheres prostitutas as quais eles poderiam ajudar financeiramente ${ }^{15}$. Além dessas afirmações restritas ao Beco da Energia, encontramos no jornal Folha do Norte várias notícias que evidenciavam que a prática prostitucional era acobertada por homens importantes, também em outras ruas, como nessa denúncia:

Inúmeras pessoas têm dirigido queixas a esta redação contra o ruído que fazem alguns cabarets de baixa categoria existentes na cidade, que não tem hora para abrir nem para fechar. Não se compreende como as autoridades policiais que proibiram o funcionamento do Boite Wender admitam que essas casas ruidosas e ruinosas casas de diversão estejam a prejudicar o

14 MCS/CENEF, Folha do Norte, Pensões alegres entre as famílias, 1951.

${ }^{15}$ Clésia, dona de uma casa de prostituição, 80 anos. Entrevista concedida em novembro de 2017. 
sossego público e a levar a inquietação ás famílias residentes nas suas proximidades (MCS/CENEF, Com a polícia, 1956).

Ao contrário de Silva (2009) e Oliveira (2008), não percebemos na figura da prostituta uma ameaça em potencial, pois as denúncias feitas pelos moradores revelavam muito mais a condição de Feira, enquanto uma urbe em desenvolvimento, com poucos postes, baixa segurança pública e com demandas de saneamento, do que uma cidade que estava determinada a banir das ruas as casas de diversões (MCS/CENEF Folha do Norte. Uma caminhonete perigosa. 1951). O discurso produzido pelo jornal, ao mesmo tempo em que colocava a responsabilidade da ordem da cidade no poder policial, denunciava-os constantemente pelas violências em que se viam envolvidos.

Da mesma forma, o envolvimento dos policiais era marcante no Jogo do Bicho, espaço considerado como reduto da imoralidade. Assim, se fossemos considerar todos os noticiários, diríamos que se tinha algum público alvo de constantes queixas, esses eram os policiais feirenses e não as mulheres prostitutas ou mesmo as donas de casas/bares de diversão. Eram os policias que ao invés de reter a desordem a provocavam, sujeitos de atos impensados que cometiam continuamente atrocidades, violentando muitas vezes até os moradores da cidade ${ }^{16}$. Desta forma, os aspectos que mais se destacaram na análise do jornal Folha do Norte não evidenciam uma perseguição à prostituição, mas nos deram margens para compreender as múltiplas identidades dos moradores de Feira e para perceber que o discurso de modernidade construído pelos jornalistas, apontava que os comportamentos contrários à preservação da civilidade na urbe feirense estaria nos homens, pois de maneira geral, as queixas feitas pelos jornalistas e pela população, se voltavam ao gênero masculino, sendo eles homens da polícia ou os chamados desocupados e malandros.

Ao longo dos anos, no entanto, principalmente após a instalação da Ditadura Civil Militar em 1964, a quantidade de denúncias que questionavam a eficiência na administração do poder público e as arbitrariedades feitas pela polícia feirense, reduziram consideravelmente. Tivemos a impressão de que na cidade feirense, havia ocorrido um desenvolvimento urbano intenso ou um silenciamento imposto pelo regime ditatorial, em

\footnotetext{
${ }^{16}$ MCS/CENEF/ Folha do Norte. Com a polícia.1956.

MCS/CENEF. Folha do Norte. Apelo, 1952.

MCS/CENEF. Folha do Norte. O Jogo em Feira, 1950.
}

Revista Espacialidades [online]. 2021.1, v. 17, n. 1, ISSN 1984-817X 
relação as desordens causadas pelos policiais e aos problemas advindos da má administração das verbas públicas, pois as constantes reclamações à falta de iluminação pública, a presença de animais soltos nas ruas da região do centro e a sujeira dos espaços públicos, deixaram de aparecer nas sessões do Folha do Norte, que passou a alertar a preservação da limpeza das ruas, através de lembretes como esse: Não joguem lixos nas ruas ${ }^{17}$ !

Acreditamos então, que essa diminuição se deve ao contexto de repressão e vigilância específico ao contexto ditatorial. Enfim, foram todas essas evidências analisadas, que nos levaram a afirmar que em Feira a perseguição à prática prostitucional não ocorreu como Silva (2009) e Oliveira (2008) observaram e que, portanto, o Beco assim não pode ser entendido como um espaço de resistência à mesma. Feita essas problematizações, nos debruçaremos logo adiante, nas discussões sobre o Beco da Energia a partir da perspectiva que põe em evidencia o seu caráter, enquanto uma zona de prostituição que também abrigavam grupos familiares.

\section{O Beco da Energia e os seus lugares de memória.}

A contestação da ideia de que os espaços prostitucionais, ou as chamadas zonas possuem apenas uma única identidade pautada pela alteridade e marginalidade, foi construída por nós, na medida em que, nos debruçávamos numa esteira de estudos sócioantropológicos, que se dedicaram a pensar as zonas de prostituição ressaltando a multiplicidade de sentidos que podiam ser atribuídas as mesmas.

Um dos trabalhos que mais nos auxiliou neste viés foi o realizado por Bacelar (1982). O antropólogo tecendo uma discussão bibliográfica a respeito do conceito de família e da identidade social, tendo como foco os arranjos familiares comandados pelas mulheres prostitutas, construiu seu texto buscando se afastar da perspectiva que pesquisa a prostituição destacando apenas o seu caráter enquanto um comércio do sexo e se propôs a compreender a dimensão familiar da vida das mulheres prostitutas. Em paralelo a isso o antropólogo apontou também a discussão acerca da identidade da área no qual a prostituição era exercida, situada no bairro do pelourinho, conhecida como o Maciel, ressaltando que, assim como em

${ }^{17}$ Do ano de 1967 em diante percebemos esse padrão no Jornal Folha do Norte. 
outros espaços de vida social neste espaço coexistiram estilos de vida, visões de mundo e práticas sociais variadas e especificas a mesma.

Outro importante trabalho que nos guiou nesta empreitada é o de Fonseca (1996). A antropóloga problematiza a inclinação percebida nos trabalhos produzidos sobre a prostituição ao se utilizar sempre de tipologias para compreender a vida de mulheres prostitutas que segundo a mesma, não pode ser enquadrada em nomenclaturas imóveis, ressaltando que, esta prática pode reafirmar os estereótipos que associam a figura dessas mulheres a polos dicotômicos, ou seja, a prostituta se torna aquela que por pobreza e com muito sofrimento é quase obrigada pela sua condição financeira a seguir nesta vida, ou as outras que se prostituem pela devassidão e desejo sexual incontrolável. Segundo a autora, na tentativa de elaborar um estudo sobre uma temática ainda pouco explorada, os autores ao se utilizarem tipologias, acabam contribuindo para fixação de uma única identidade das mulheres prostitutas, ligada à sexualidade, sem explorar, os demais campos de atuação em suas vidas, como por exemplo, a maternidade, e o trabalho no lar.

Diante dessa reflexão, ao passo que liamos o trabalho de Silva (2009) e Oliveira (2008) nos incomodou inclusive a denominação dada às ruas em que ocorria a prostituição e as mulheres que a praticavam, pois, ao classificar estes espaços e sujeitos dentro da tipologia dos excluídos feirenses, que segundo as historiadoras causavam desconforto entre as famílias da cidade, perguntávamos, e as mulheres prostitutas não tem família? E as donas de casas alegres também não tinham famílias? Percepção que ficou ainda mais problemática ao realizarmos uma análise sobre o perfil das pessoas entrevistadas e percebermos, que muitos deles tinham lembranças sobre o Beco da Energia relacionadas à suas vivências familiares e não somente a prática prostitucional.

Através das suas falas, o Beco foi se mostrando também como um lugar de memória de família, indo na contramão dos trabalhos produzidos sobre as ruas e becos feirenses que abrigavam a prostituição, uma vez que, em nenhum deles a dimensão afetiva vivenciada pelos seus moradores através dos laços de parentesco, foi evidenciada. Para Nora (1993) os lugares de memória podem se referir tanto aos espaços físicos, quanto a objetos que adquirem um significado através dos sentidos que os sujeitos atribuem ao mesmo. $\mathrm{O}$ autor ressalta que quando se fala em lugares, ele está pensando essa palavra e, portanto, o seu próprio conceito, 
levando em consideração as três possibilidades de sentido, sendo assim, os lugares de memória, fazem referência a aspectos materiais, simbólicos e funcionais.

Diante dessas premissas quando me voltei a análise das lembranças dos meus entrevistados, fui notando que ao falar do Beco surgiam características desse espaço que me informaram aspectos mais sólidos do mesmo, como a quantidade de casas, mas também outros dados, que o colocaram dentro deste trabalho como um local ao qual se pôde perceber o teor simbólico dos lugares de memória que Nora (1993) alerta. Isto ficou mais evidente, na medida em que, todas as entrevistas, mesmo sendo direcionadas pelo questionário elaborado, foram convergindo para momentos pontuais do cotidiano dos moradores e vizinhos do Beco, que pareciam repetir um discurso único. Os entrevistados ressaltavam repetitivamente, que a rua era um espaço "normal" e que lá existiam casas de família e de prostituição, com exceção apenas do comerciante Arnaldo que afirmou haver na rua apenas casas de prostituição, denominando o Beco como "a morada delas ${ }^{18 "}$.

Porém, ao longo das entrevistas, todos lembraram-se dos limites impostos as crianças em relação ao horário adequado para permanecer na rua, denotando não apenas que haviam regras básicas de convivência entre as donas de casas/bares de diversão e a ditas casas de família, mas também que essas crianças eram criadas dentro de um círculo familiar ao qual o chefe dos seus lares eram as mesmas mulheres que administravam encontros com as prostitutas. Assim o final da tarde, mais especificamente às 17 horas, não pareceu ser somente uma hora do dia como outra qualquer, mas um lugar de memória, a qual os adultos que entrevistamos lançavam mão quando precisaram se lembrar das suas vivências.

Para Dona Clésia e a falecida M. Greice, significava o espaço de tempo em que elas começavam a receber os homens-clientes em suas casas/bares de diversão, mas também o mesmo período o qual M. Greice tinha que vigiar os seus filhos para que eles não saíssem a rua, que a noite ganhava uma feição mais ligada à prostituição. Já para Maria e Suzana o fim de tarde era o momento em que segundo elas, todos os seus irmãos entravam em casa e só saiam no outro dia com a permissão da Mãe. Maria observou que ela e suas irmãs mocinhas,

18 Arnaldo, comerciante, 60 anos. Entrevista concedida em fevereiro de 2018. 
ficavam "tudo dentro de casa, tudo guardada dentro de casa", e que o único dia que elas tinham o direito de sair e brincar até às cinco horas da tarde era aos domingos ${ }^{19}$.

Outros lugares de memória ligados a uma temporalidade também foram narrados por elas e pelos demais entrevistados, referindo-se aos momentos de rezas, de alimentação em família e dos dias festivos. É o caso do caruru de Cosme e Damião realizado no mês de setembro por Madame Greice, que segundo Dona Clésia atraía os moradores de toda região do centro, como o comerciante Arnaldo ${ }^{20}$. Esse senhor afirmou que junto aos seus quatro irmãos, ele jamais perdeu um caruru de sete meninos na casa de M. Greice, sendo para ele um momento o qual podia ir ao Beco com autorização dos seus pais e se divertir. Dona Marina, por sua vez, ressaltou que durante as suas visitas ao espaço, mesmo no período da noite, muito do que presenciou foi um convívio em família, no qual existiam rezas, carurus, mas tudo entre a família de sua sogra ${ }^{21}$.

$\mathrm{Na}$ análise dessas falas é claro que devemos levar em conta, que talvez esses moradores, quisessem se afastar de uma narrativa que os colocaria como moradores de espaços "promíscuos". Mas se formos um pouco adiante, podemos analisar que nem o discurso do jornal Folha do Norte, nem as falas dos entrevistados apontam verdades absolutas, mas apenas pontos de vistas diferentes e que longe de ser um problema para esse trabalho, puderam nos ajudar a entender que no Beco coexistiam casas residências, que poderiam ser, ao mesmo tempo, pequenos comércios e espaços de prostituição. Ademais, essas memórias mesmo esparsas e confusas em muitos momentos, nos auxiliaram a compreender um pouco do cotidiano em família e a forma como as mesmas eram estruturadas.

Essas famílias, eram basicamente estruturadas em um formato na qual a figura do provedor do lar era centrada nas mães, que criavam seus filhos a partir dos seus trabalhos: vendendo balas, pipocas, cervejas, refrigerantes, servindo os almoços ou administrando uma casa/ bar de diversão. Dado que nos apontam a persistência dos arranjos familiares centrados

\footnotetext{
${ }^{19}$ Suzana, manicure, aposentada, 63 anos. Entrevista concedida em outubro de 2017.

Maria, dona de uma casa de prostituição, 59 anos. Entrevista concedida em outubro de 2017.

${ }^{20}$ Clésia, dona de uma casa de prostituição, 80 anos. Entrevista concedida em novembro de 2017.

21 Marina, ex- faxineira, ex-aposentada, 72 anos. Entrevista concedida em julho de 2016.
} 
na matrifocalidade, experiência bastante comum entre as camadas pobres soteropolitanas do início do século XX investigadas por Filho (1994) mas que foram igualmente encontradas por mim num recorte posterior.

É necessário ressaltar, no entanto, que quando falamos em família neste trabalho nos referimos aos indivíduos que viviam dentro de uma mesma casa geralmente habitada por crianças, pois sempre que os entrevistados se referiam as famílias existentes no Beco eles evidenciavam a presença de crianças dentro desses lares, como sendo um elemento que definia ou não grupo familiar. Um exemplo disso é que, quando dona Clésia descreveu as casas da rua, esta senhora em nenhum momento considerou que ela e sua irmã gêmea se constituiriam como uma família, sempre apontando para as crianças como elemento identificador de um grupo familiar, um padrão que Bacelar (1982) observa que é característico de famílias chefiadas por prostitutas ou por mulheres que estão envolvidas com tal prática, como é o caso de M. Greice ${ }^{22}$.

Diante dessa possibilidade de arranjos familiares que destoavam do padrão burguês, o qual a família deve ser composta por pai, mãe e filhos, pudemos compreender e propor que, talvez, na cidade feirense, sobretudo entre os indivíduos pobres e moradores dos Becos, para um grupo de pessoas se constituírem ou não como um grupo familiar, o critério estava muito mais relacionado à existência de filhos consanguíneos do que propriamente a uma permanência de um arranjo familiar nos moldes burgueses. Isso pode justificar a convivência amigável tão defendida pelos entrevistados entre as famílias que moravam no beco e os demais moradores da cidade.

Isso também pode confirmar, que a pouca quantidade de denúncias no jornal Folha do Norte às casas/bares de diversão, localizadas próximas às casas das ditas, "famílias feirenses", se explica pelo fato de que não era a ocupação das mães como donas e administradoras de um casa/bar de diversão o que provocava um conflito direto com os demais moradores, uma vez que para os nossos entrevistados, o que era crucial para um bom convívio entre os vizinhos era o respeito a todos, ou seja, não falar palavrões em público e não andar de roupas curtas e "devassas".

${ }^{22}$ Clésia, dona de uma casa de prostituição, 80 anos. Entrevista concedida em novembro de 2017. 
Foi a partir destas questões lançadas que o nosso olhar sobre o cotidiano do Beco da Energia foi se ampliando e passamos a enxergar neste espaço, uma rua sim de prostituição, mas dentro de uma ótica na qual a existência desta prática não anulava a coabitação de vivências relacionadas a outros aspectos da vida dos moradores da mesma. O Beco passa a se constituir neste trabalho, com o que Certeau (1998) vai denominar de um lugar praticado, sendo entendido como palco das operações praticadas que o circunstanciam, o temporalizam e o levam a funcionar em unidade polivalente de programas que podem ser conflituais ou de proximidades contratuais. Para Certeau (1998) o conceito de lugar está relacionado à ideia de estabilidade e imobilidade. Contraditoriamente o espaço seria por sua vez o templo por excelência da impermanência, no qual deve ser levado em conta vetores que perpassam por uma multiplicidade de interpretações que são marcadas pela temporalidade e por uma dinâmica que está o tempo todo trocando as coisas do lugar. O Beco da Energia se configura então como um lugar, apenas no sentido da imobilidade das estruturas fixas das casas ali construídas, mas como um espaço está sempre em transmutação, se reconstruindo-se a cada novo dia.

É importante ressaltar que não queremos com todas estas problematizações silenciar a possível estigmatização dos sujeitos que conviviam cotidianamente com prática prostitucional no Beco, ou afirmar que não existia nenhum conflito por conta do preconceito em relação aos moradores do mesmo, mas realizar um estudo, no qual outras memórias relacionadas muito mais a vínculos afetivos pudessem ser palco de uma análise historiográfica.

\section{Considerações finais}

Em finais do ano de 1960, o cotidiano do Beco da Energia vivenciado entre as décadas de 1950-1960, passou por uma grande modificação, momento que foi datado com bastante precisão por todas as pessoas as quais entrevistamos, pois elas afirmaram que foi a partir do ano de 1969 que o Beco deixou de abrigar famílias (ou seja, crianças) e casas/bares de diversão para ser habitado apenas por pessoas que trabalhavam diretamente com a prática prostitucional, sendo essas: as mulheres prostitutas e as donas das agora chamadas de "casas de prostituição" ou "prostíbulos". 


\section{Espacialididades}

Nas suas falas, porém, ficou evidente que a modificação dessa nomenclatura estava relacionada a uma mudança em relação à própria concepção sobre a prostituição e as mulheres prostitutas, uma vez que, eles apontam que as prostitutas foram ficando cada vez mais "imorais" e "vulgares", trajando roupas curtas, o que gerou ao longo dos anos, uma falta de respeito da sociedade a elas. Elas ressaltaram ainda, que as mulheres de uma forma geral, foram perdendo a compostura e passando a se vestir com roupas curtas e devassas. $\mathrm{Na}$ leitura do jornal Folha do Norte dos anos de 1960, no entanto, não encontramos nas notícias elementos suficientes que indicassem tal modificação em relação aos hábitos das mulheres feirenses, nem tampouco, denúncias que pudessem nos esclarecer acerca da retirada das crianças do Beco da Energia.

Percebemos que a década de 1970 apresenta diversos significados, que, para os trabalhos historiográficos que analisaram a prostituição, se resume a uma reorganização espacial definida por valores morais que retiraram das ruas e becos as casas/bares de diversão. Em contrapartida, as memórias dos antigos moradores e vizinhos do Beco apontam outras perspectivas que nos levam a entender que as casas/bares de prostituição na região do centro não foram exterminadas, mas apenas revestida por outras características para usufruir inclusive, desse intenso fluxo de pessoas que circulam atualmente, entre os pontos comerciais na cidade. Feição adquirida a partir dos anos de 1960.

Dessa forma, não compreendemos a permanência da prostituição no Beco da Energia como uma resistência de fato, pois, acreditamos que se por um lado existiu uma preocupação em apartar as crianças do convívio com a prática prostitucional que se modificava, por outro lado não houve um intensão direta de acabar com a prostituição de um local. Assim, concluímos este trabalho chamando atenção para as precipitações analíticas que podem ser tomadas quando os historiadores desconsideram o discurso dos indivíduos que moravam em ruas que existia a prostituição, ao notar que o cruzamento das entrevistas orais com as demais fontes nos ofereceram uma rica contribuição para entendimento das múltiplas identidades que tanto os moradores do Beco quanto o espaço assumiam cotidianamente. 


\section{FONTES ORAIS}

ARNALDO, Depoimento (fev. 2018). Entrevistador: Lucymara da Silva Carvalho. Entrevista concedida para pesquisa sobre o Beco da Energia.

CLESIA, Depoimento (out. 2017). Entrevistador: Lucymara da Silva Carvalho. Entrevista concedida para pesquisa sobre o Beco da Energia.

MARINA, Depoimento (julh. 2016). Entrevistador: Lucymara da Silva Carvalho. Entrevista concedida para pesquisa sobre o Beco da Energia.

SUZANA, Depoimento (out. 2017). Entrevistador: Lucymara da Silva Carvalho. Entrevista concedida para pesquisa sobre o Beco da Energia.

\section{REFERÊNCIAS}

BACELAR, Jeferson Afonso. A família da prostituta. São Paulo: Ática; Salvador: Fundação Cultural do Estado da Bahia, 1982.

CARVALHO, L.S. Beco da Energia: Modernização, desterritorialização e marginalização do comércio prostitucional em Feira de Santana-BA. In: VIII Encontro Estadual de História- Espaços de História. UEFS, 2016. Feira de Santana. Anais Eletrônicos... Feira de Santana, UEFS, 2016.Disponível em:< http://www.encontro2016.bahia.anpuh.org/resources/anais/49/1477440087_ARQ UIVO_TextodaAnpuh2016.pdf>. Acesso em 31 de agosto de 2020.

CERTEAU, Michel de. A invenção do cotidiano: artes de fazer. $3^{\circ}$ edição. Tradução de Ephraim Ferreira Alves. Petrópolis. Vozes, 1998.

CUNHA, Maria F. Mulher e a historiografia: da visibilidade à diferença. Hist. Ensino, Londrina, v. 6, p. 141-161. 2000.

FERREIRA FILHO, Alberto Heráclito. Salvador das Mulheres: condição feminina e cotidiano popular na Belle Époque Imperfeita. Dissertação (Mestrado em História) - Universidade Federal da Bahia, Salvador, 1994.

FONSECA, Claudia. A Dupla Carreira da Mulher Prostituta. Revista Estudos Feministas. Rio de Janeiro, IFCS / UFRJ - PPCIS / UFRJ, vol. 4, nº 1, 1996.

LIMA, Carlos Alberto. Das luzes e becos: cartografias e imagens do "complexo Rua do Meio" (1940- 1960) Dissertação (mestrado) Universidade Estadual de Feira de Santana, Feira de Santana, 2014.

NORA, Pierre. Entre Memória e História - a problemática dos lugares. Trad. Yara aun Khoury, São Paulo, n.10, 1993. 
OLIVEIRA, Ana Maria Carvalho dos Santos. Feira de Santana em tempos de modernidade. Olhares, imagens e práticas do cotidiano (1950-1960). Tese de Doutorado. Recife, UFPE, 2008.

PESAVENTO, Sandra Jatahy. Uma Outra Cidade: o Mundo dos Excluídos no Final do Século XIX. São Paulo: Companhia Editora Nacional, 2001.

POLLAK, Michael. Memória e Identidade social. Estudos históricos. Rio de Janeiro, vol. 5. n. 10, 1992, p. 200-212.

PORTELLI, Alessandro. A Filosofia e os Fatos: Narração, interpretação e significado nas memórias e nas fontes orais. Tempo. Rio de Janeiro, v. 1, n. 2, p. 59-72, 1996.

RAGO, M. Os prazeres da noite: Prostituição e códigos da sexualidade feminina em São Paulo. Rio de Janeiro: Paz e Terra, 1991.

SILVA, Maria Carolina Silva Martins da. Nas veredas dos discursos moralistas: a honra das mulheres em Feira de Santana, Bahia (1960-1979). Dissertação (mestrado) Universidade Federal da Bahia- Faculdade de Filosofia e Ciências Humanas, 2009.

TEIXEIRA, António F. Espaço social e suas representações. Sociologia: Revistada Faculdade de Letras da Universidade do Porto, n. ${ }^{\circ}$ 2, 1992. 